\title{
Actualismo y presente amplio: breve análisis de las temporalidades contemporáneas*
}

\author{
MATEUS HENRIQUE PEREIRA Y VALDEI LOPES DE ARAUJO
}

Mateus Henrique Pereira

Universidade Federal de Ouro Preto,

Minas Gerais, Brasil

matteuspereira@gmail.com

VALDEI LOPES DE ARAUjo

Universidade Federal de Ouro Preto,

Minas Gerais, Brasil

valdei354@gmail.com
Discutimos sintomatologías relacionadas con una ruptura entre el tiempo historicista-moderno, por lo general encontrado en el siglo XIX, y un "cronotopo" o "régimen de historicidad" emergente, sustancialmente distinto. Después de leer "Temporalidad y cotidianidad", de Ser y tiempo, de Heidegger, argumentamos que ciertos aspectos de este tiempo pueden derivarse de las descripciones de la temporalidad del "estado de apertura". Por lo que para Heidegger estas formas de experiencia son ontológicas, tendríamos que pensar en el significado de su "pérdida de relevancia" en las descripciones de la "época moderna" y su hipertrofia en las descripciones de la novedad de nuestro actual cronotopo. Utilizamos la palabra "actualismo" para pensar en una forma de presente que pone el énfasis en las temporalizaciones no auténticas.

PALABRAS CLAVE: presentismo, presente amplio, actualismo, Heidegger, temporalidades

Updatism, and Broad Present: A Brief Analysis of Contemporary Temporalities

We discuss some symptomatologies of our present time that claim substantial differences between the historicist-modern time, usually located in the $19^{\text {th }}$ century, and an emergent "chronotope" or "regime of historicity". From the chapter "Temporality and everydayness", of Being and Time, we argue that certain aspects of this new "chronotope" can be derived from Heidegger's description of the temporality of "openness", particularly of what he calls the inauthentic temporalizing. Since for Heidegger these forms of experience are ontological, we have to consider the meaning of their irrelevance in the descriptions of the "modern time" and its hypertrophy in the descriptions of the so-called novelty of our "chronotope". We use the word "updatism" as an alternative to understanding our historical time.

KEYWORDS: presentism, broad present, updatism, Heidegger, temporalities 
Actualizo, luego existo.

@ajkeen (2012)

n el presente artículo discutiremos la sintomatología actual que apunta a una ruptura decisiva entre el momento historicista-moderno, por lo general situado en el siglo XIX, y un "cronotopo" (Gumbrecht, 2014) o "régimen de historicidad" (Hartog, 2003) emergente, que sería sustancialmente distinto. En más de un aspecto, los relatos de Gumbrecht y Hartog coinciden en la descripción de lo que el primero llama "presente amplio", y el segundo, "presentismo".

A partir de la lectura del capítulo "Temporalidad y cotidianidad”, de Ser y tiempo, de Martin Heidegger (1993: 93-129; 2003: 324-359; 2006: 301-333; 2010: 319354), ${ }^{1}$ argumentamos que ciertos aspectos del tiempo, apuntados como síntomas de una transformación histórica de la experiencia, pueden derivarse de las descripciones de Heidegger de la temporalidad y el "estado de apertura" —Erschlossenheit—, en particular de la dimensión "inauténtica" e "impropia”. Dado que para Heidegger estas formas de experiencia son ontológicas, sería necesario reflexionar sobre el significado de su "ocultamiento" relativo en las descripciones de "tiempo moderno"

* $\quad$ Agradecemos el apoyo e interlocución de nuestros colegas del Núcleo de Estudos em História da Historiografia e Modernidade de la Universidade Federal de Ouro Preto (UFOP) y de la Sociedade Brasileira de Teoria e História da Historiografia, en especial a Temístocles Cezar, Fernando Nicolazzi, Júlio Bentivoglio, Sergio da Mata, Marcelo Abreu, Marcelo Rangel, Luisa Rauter, Henrique Estrada, Tamara Rodrigues, André Ramos, Augusto Ramires, Guilherme Bianchi, André Freixo y Helena Mollo. Apreciamos el apoyo de la Coordenação de Aperfeiçoamento de Pessoal de Nivel Superior, el Conselho Nacional de Desenvolvimento Científico e Tecnológico, la Fundação de Amparo à Pesquisa do Estado de Minas Gerais y la UFoP.

1 Seguimos la traducción de Jorge Eduardo Rivera (Hedeigger, 2003) y la comparamos con la traducción brasileña de Márcia de Sá Cavalcante (Heidegger, 1993). En diversos momentos las confrontamos con la traducción al inglés estadounidense, de Joan Stambaugh (Heidegger, 2010) y con la edición original alemana (Heidegger, 2006). 
y su hipertrofia en las descripciones de la reivindicada novedad de nuestro cronotopo o régimen de historicidad. $^{2}$

Para avanzar en la caracterización del impasse de las descripciones de nuestra historicidad, utilizaremos la palabra "actualismo" —updatism-, derivada de la expresión inglesa update, para pensar en una forma de presente que destaque las temporalidades inauténticas. Éstas, a pesar de estar siempre activas en otros momentos históricos, no sólo se están convirtiendo en las predominantes de la cotidianidad, sino que se presentan como la única forma posible y deseable de temporalidad en la era digital.

Del mismo modo en que Ricoeur (2012) subraya la importancia de la diferenciación de Heidegger entre el "pasado" y la "fuerza de haber sido", ${ }^{3}$ nuestra hipótesis es que podemos ampliar esa comprensión a la dimensión heideggeriana del "presente". Aunque resulta menos evidente, en Ser y tiempo el presente también posee varias dimensiones. Así, uno de los problemas de la reflexión sobre el presentismo es que no está lo suficientemente atento a esas formas del presente, en especial al hecho de que cualquier forma de presente contendrá en sí misma formas específicas de pasado y de futuro.

\section{El surgimiento de la palabra update como concepto revelador}

Según los diccionarios etimológicos de lengua inglesa, el uso corriente de la palabra update se remonta a 1940-1945. Una búsqueda en Google Libros ${ }^{4}$ revela algunas referencias aisladas a lo largo del siglo XIX. Encontramos casos de uso de la expresión a comienzos del siglo Xx en un sentido de "actualización": llevar una lista o un conocimiento a un estado más completo. Sin embargo, no es sino hasta las décadas de 1960 y 1970 cuando los casos se multiplican y su asociación a la cultura de la computadora comienza a definir mejor su campo semántico.
En un folleto del Centro de Información Técnica de Defensa de 1967, un software llamado Update prometía ser "una solución provisional al problema básico que todo sistema de datos enfrenta en un entorno en tiempo real: pérdida total de los datos sin procesar, durante los modos de diagnóstico y recuperación derivados de errores de funcionamiento" (Cameron, 1967).

Una búsqueda en diccionarios contemporáneos de lengua inglesa nos lleva al siguiente campo de sinónimos para la forma verbal "to update": amend, modernize, refresh, refurbish, rejuvenate, renew, renovate, restore, revise. En la gráfica 1, comparamos la evolución del léxico update en la base de lengua inglesa de Google Ngram. ${ }^{5}$ Ahí se verifica que el aumento

En este sentido, encontramos prometedora la propuesta de Jordheim, de relativizar la visión homogénea de las historicidades modernas: "a lo largo de toda su existencia, pero quizá especialmente al momento de su surgimiento en el siglo XVIII, y en la actualidad, durante su colapso, el régimen de temporalidad identificado como moderno ha sido desafiado por otros tiempos, otras temporalidades, más lentas, más veloces, con ritmos distintos, otra sucesión de eventos, otras narrativas, etcétera" (2014: 502). En la misma tónica, véase Bevernage (2012).

Entre otras cosas, Paul Ricoeur señala que, al menos para él, "san Agustín y Heidegger son, en efecto [...], los únicos pensadores que tomaron como tema rector de su concepción del tiempo la dialéctica del pasado, presente y futuro" (2012: 338). Sobre todo en Heidegger, "parece evidente que el problema de diferenciación de las tres instancias del tiempo [se establece] a partir de su presunta unidad [...]. Se identifica entonces, además del tema de la pluralización e incluso de la dispersión de las tres instancias, el de su articulación" (2012: 339). Véase también Ricoeur (2000).

Véase <https://books.google.es>.

Acerca de los cuidados y potencialidades del uso de este instrumento, véase Pereira, Dos Santos y Nicodemo (2015). Para el uso de la palabra "actualismo" - actualism - en geología y filosofía, véanse, entre otros, Faria (2014); Menzel (2014). Aunque poco difundida y con otro sentido, en inglés existe la palabra actualism, derivada de "cierto", "real", en el sentido de "efectivo". No obstante, esa palabra no abarca los sentidos que queremos subrayar por medio de la expresión updatism. 


\section{Google Books Ngram Viewer}

Graph these comma-separated phrases: Kigital, web, virtual, update
between 1900 and 2000 from the corpus English case-insensitive

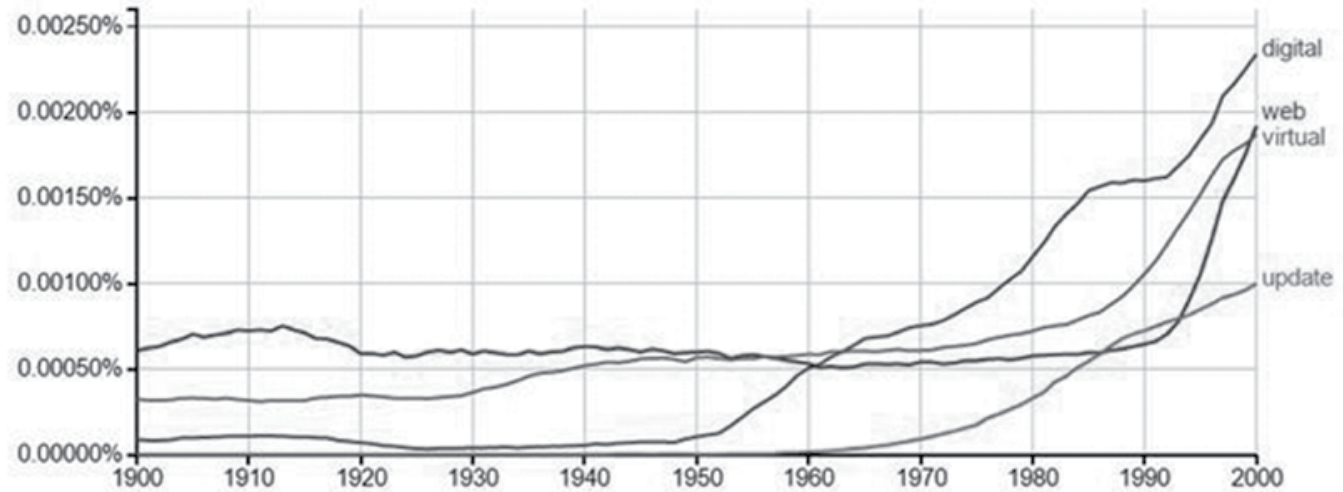

Fuente: Google Books Ngram Viewer. Consultado el 23 de junio de 2017.

de la frecuencia de uso de la palabra comienza a mediados de la década de 1960, pues al parecer recibe parte de su valor semántico de conceptos más antiguos que ya se utilizaban para caracterizar una mejoría o dinámica positiva en cierto estatus, como progress e improvement. La curva ascendente de update parece acompañar a la nueva realidad digital, como se observa en el incremento en el uso de palabras como web, virtual y digital.

La expresión que proponemos como categoría para definir ciertos aspectos de la temporalidad contemporánea, updatism, puede encontrarse en algunos sitios de internet. Los usuarios de foros de juegos, fanfictions y blogs la emplean como una especie de marcador para publicaciones, cuya función principal es actualizar un tema. Surge como una variación espontánea y marginal de update, que parece traducir la dificultad de hacer real el "tiempo real" de la experiencia en esos entornos digitales y patrimonializados. Al mismo tiempo, denuncia el problema de la adicción a lo actual: a los usuarios se les dificulta escapar del flujo de las novedades.

En la quinta edición del American Heritage Dictionary of the English Language, la palabra update tiene funciones de verbo y sustantivo. ${ }^{6}$ Como verbo, puede indicar la acción de modificar algo para traerlo al día de hoy, al momento actual: update a textbook, update the files, y para informar a alguien de las últimas noticias. La expresión latest information, utilizada a manera de garantía, está en su forma superlativa, pero también puede aparecer como sustantivo en la frase the latest in electronic gadgetry, también como garantía. Update puede usarse para referirse a un informe o relato que busca actualizar la información sobre determinado hecho o incluso para señalar la acción de hacer algo más moderno, para

6 Disponible en línea: <https://ahdictionary.com/word/search. html?q=update $>$. 


\section{Google Books Ngram Viewer}

Graph these comma-separated phrases: bctualización
between 1900 and 2000 from the corpus Spanish case-insensitive

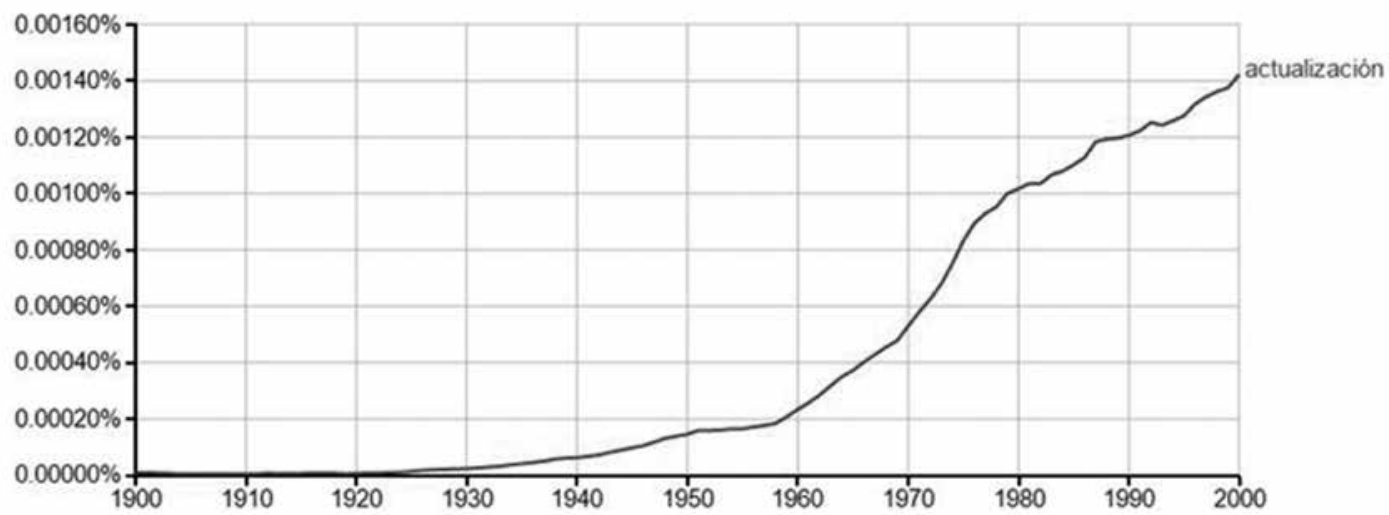

Fuente: Google Books Ngram Viewer. Consultado el 23 de junio de 2017.

modernizar, siempre con el sentido de mejorarlo o de hacerlo corresponder al tiempo más reciente, a lo que está de moda. La presión por estar up to date, por ser un contemporáneo del propio tiempo, no es extraña en esta modernidad historicista, como hemos mencionado. El fenómeno de la moda durante el siglo XIX ya se describía — por ejemplo, en Baudelaire- como una presión de la cual no era posible escapar sin consecuencias (Agamben, 2009).

Sin embargo, incluso desde el siglo XIX, dicha presión por el cambio se matizaba con imágenes que se compartían en colectivo y que parecían dotarla de sentido y estabilizarla. Instituciones y nuevos profesionales surgieron para orientar al ciudadano en la tarea de habitar "su tiempo", el cual era nacional, moderno o civilizado (Zermeño, 2008). Al debilitarse estas directrices mediadoras, la presión por estar actualizado o "en su tiempo" se acelera al punto de volverse paradójica. El encuentro consigo mismo o con el tiempo propio, con la disposición de un lugar estable — la nación, las identidades - y un tiempo formativo, ahora parece posponerse hasta la eternidad, ya que el tiempo se ha disminuido y el espacio se ha virtualizado. El lado positivo es la flexibilización de las identidades, lo que nos permite pensar en fenómenos como el uso de avatares, la vida de ficción en los foros - fanfics - o el entregarse al flujo ininterrumpido de las variedades. Pertenecer a un tiempo puede exigir estar conectado $24 / 7^{7}$ a un canal de noticias en flujo continuo o ser parte de la "historia" al reaccionar ante los grandes acontecimientos en tiempo real en las redes sociales.

No sólo en inglés gana influencia la concepción de una realidad o situación que se intensifica de manera continua y alcanza un estatus de contemporaneidad permanente, si entendemos la palabra

7 Es decir, 24 horas al día, siete días a la semana. 
actualización como una de las que concentra esa nueva dimensión de la experiencia histórica del tiempo. En la gráfica 2, vemos que su evolución en la base de libros en español apunta hacia un movimiento similar.

\section{Gumbrecht: ambivalencias del presente amplio}

En el último ensayo de su libro Our Broad Present, Gumbrecht (2014) analiza las relaciones entre tecnologías digitales y temporalidades. Aun cuando su perspectiva es muy pesimista, no deja de señalar oportunidades o brechas de la nueva situación, al mismo tiempo que celebra lo que considera un agotamiento de la modernidad. Si todo está a disposición y todos disponibles, la tecnología de la información corre el riesgo de destruir las condiciones para el pensamiento, pues éstas dependen de una oscilación entre "presencia" y "sentido". Mientras que Hartog $(2003$; 2013) y otros autores (Fontana, 1998; Arantes, 2014), por lo regular críticos del supuesto fin o agotamiento de la modernidad, lamentan la pérdida de un futuro abierto, de la utopía, del sentido histórico, Gumbrecht (2014) se propone ver, en esos mismos diagnósticos, oportunidades para profundizar en una cultura del cuerpo y de la presencia. $^{8}$

No obstante, parece oscilar entre el optimismo mesurado por la pérdida de las grandes narrativas y el pesimismo ante la percepción de que dicha pérdida podría ser fruto, no tanto del agotamiento, sino de la profundización de la cultura del sentido en la era digital. Contra su propio deseo de establecer una ruptura que libere a nuestro tiempo de "la modernidad", su relato también abre la posibilidad de una interpretación opuesta. Su descripción del deseo de "presentificación", como síntoma de nuestro tiempo, puede también ilustrar la agonía de las prácticas de la presencia, más que su generalización reactiva y compensatoria.
Después del comienzo del ensayo "Disponibilidad infinita. Acerca de la hipercomunicación (y la vejez)", Gumbrecht (2014: 61-72) asegura encontrarse entre aquellos que se sienten desplazados en el entorno digital. Se ha opuesto en la medida de lo posible a las innovaciones tecnológicas y defiende su decisión con una disciplina rigurosa que limita su tiempo de uso de herramientas como el correo electrónico. El relato despierta nuestro interés cuando menciona la "actualización automática" —automatic upgrading - del software de su computadora de trabajo, que comparte buzón de correo con otra computadora doméstica, uno de los efectos y posibilidades de la computación en nube — cloud computing-.

8

Por razones de espacio, haremos una alusión breve a la reflexión de François Hartog, quien en su libro de 2013 desarrolla y sustenta sus tesis de 2003. Afirma, por ejemplo, lo siguiente: "[Péguy] dio el golpe, el más duro, a saber, el cambio progresivo de nuestras relaciones con el tiempo, del futuro al presente: la clausura del futuro y la expansión de un presente omnipresente, al que nombré presentismo. Con esta paradoja, señalada por Marcel Gouchet, el futuro desaparece del horizonte, a pesar de que consiguió 'incrementar', como nunca, nuestra capacidad de producir. Aún más que imprevisible, se tornó 'inimaginable'” (2013: 30). Incluso: "el futuro, al final, se convirtió en un lastre que las personas, empresas o instituciones no pueden soportar más [...]. Del futuro hacemos tabula rasa [...]. Y para el pasado, están la memoria (con el patrimonio y la conmemoración) y la justicia: para juzgar la historia de ayer, la de anteayer o la de hoy mismo" (2013: 103). En 2013, cercano a la conclusión de 2003, advierte: "si hay una vida para la historia después del concepto moderno de historia, pasa, a su vez, por la capacidad de nuestras sociedades de articular de nuevo las categorías de pasado, presente y futuro, sin que llegue a instaurarse el monopolio o la tiranía de alguna de ellas, y por la voluntad de comprender nuestro presente. Los dos procesos están íntimamente vinculados. Y esta vida, atada al 'recuerdo' y abierta a la 'esperanza', para hablar en términos de Novalis, todavía está por inventarse” (2013: 299) [todas las traducciones del francés son de Livia VargasGonzález]. Acerca de la perspectiva de Hartog, véase, entre otros, Nicolazzi (2010). Para semejanzas y diferencias entre Hartog y Gumbrecht, véase, entre otros, Pereira y Da Mata (2012). 
Aun cuando reconoce el carácter democrático y el lado positivo de ese nuevo recurso, el énfasis de Gumbrecht, así como de otros analistas del mismo fenómeno (Keen, 2012), ${ }^{9}$ recae en la reciprocidad ambivalente del proceso: estar on line significa disponer de otra persona en cualquier momento, pero también estar cada vez más uno mismo a disposición de los demás. Gumbrecht no niega la naturaleza hasta cierto punto ludita de su resistencia ni el prejuicio de que entregarse a esos nuevos recursos conllevaría cierta decadencia intelectual. Aunque evita hacer explícito el aspecto nostálgico de su postura, es claro que dicha nostalgia está presente en alguna medida. La imagen de una especie en decadencia, si bien no se profundiza, sí se refuerza con algunos ejemplos de los daños colaterales del uso del correo electrónico y las redes sociales, los cuales no eran tan evidentes en 2011, año de la primera edición del libro.

La primera enunciación que complejiza la idea de una mera nostalgia nos llama la atención hacia cierto compromiso "ético", de una ética ciertamente muy personal, de no permitir que desaparezcan objetos y situaciones con los cuales hemos crecido, que constituirían nuestro "ser en el mundo" y estarían amenazados por los últimos saltos evolutivos. En un contexto en el que se entrevé la presión por un continuo y acelerado desarrollo tecnológico, que amplía la disponibilidad de todo, incluso de nosotros mismos para los demás y sus procesos tecnológicos, Gumbrecht espera que algunos objetos y situaciones con los cuales está acostumbrado a vivir se mantengan y existan durante algún tiempo más.

En un tono confesional, característico de su prosa, reconoce que su oposición a la tecnología quizá se deba al miedo que le provoca no sentirse capaz de utilizarla con la excelencia que se espera de él, debido a su desempeño intelectual. Esa pericia y naturalidad de conducta sólo se adquiere con dedicación y esfuerzo. Pone como ejemplo a los pasajeros de un avión que, tras quedarse algunos momentos sin conexión durante el vuelo, revisan con ansiedad sus celulares conforme el avión toca tierra. Aventura la hipótesis de que intentan avisar de su llegada a quien los espera en el aeropuerto: "en el momento en que un pasajero recién llegado abrace a su esposa, quizá sienta que ha llegado 'demasiado', que su cuerpo, el cual apenas ahora se incorpora a la mente y voz presentes, no ocupa un espacio existencial” (2014: 1473).

El agotamiento de la presencia física por la disolución de la presencia virtual es excesiva. Aquí su diagnóstico ofrece un punto importante sobre aquello que queremos llamar actualismo: en su tipología de "cultura de la presencia" contra "cultura del sentido", el actualismo sería la hipertrofia del sentido. Lo que podemos discutir es el lugar que ocupa un cronotopo no historicista en un mundo cada vez más historicista. ¿Aquel deseo de superación de la modernidad sería acaso una especie de reacción compensatoria? Su discurso a todas luces antimoderno, ¿no perdería su lugar en un mundo que ya no representa el fin de la modernidad, sino su desarrollo más extremo?

Gumbrecht incluso pone como ejemplo las ponencias para las que se piden versiones previas del texto a presentar y la autorización para filmar. Este registro excesivo anula el carácter propio del hecho de dar una ponencia: "nada es realmente nuevo, nada se pierde” (2014: 1502). ¿Síntomas del actualismo? En esta cultura de innovación continua, vale la pena preguntarse si todavía queda lugar para las "diferencias". En una historia acelerada,

Véase en especial su interesante reflexión acerca de un mensaje instantáneo que envió alguien Ilamado @aijkeen: "I update, therefore / am", el cual sirve de epígrafe al presente texto. 
hambrienta de "eventos" nuevos, parece que no sucede nada realmente distinto. ${ }^{10}$

Asimismo, rechaza la idea de que una discusión electrónica en realidad produzca intensidad intelectual y nociones nuevas. Incluso ha llegado a asegurar que las discusiones electrónicas producen, en el mejor de los casos, "mediocridad intelectual". ¿Estamos de acuerdo con un juicio tan definitivo? ¿No será que éste es resultado, en parte, de su confesada falta de pericia al lidiar con los medios nuevos? Si la digitalización es una extensión de una modalidad propiamente moderna, debería ser capaz de producir alguna intensidad intelectual, si bien no intensidad de presencia, al menos intensidad de sentido. Quizá para Gumbrecht las palabras "intensidad" y "sentido" son incompatibles, ¿estará en lo correcto?

Esta duda parece alimentar su ambivalencia en lo que respecta a la caracterización de nuestro tiempo como marcado por el surgimiento de un nuevo cronotopo y como la realización extrema de los tiempos modernos. Lo anterior queda de manifiesto en el siguiente pasaje: "ésa es la razón por la cual la hipercomunicación electrónica lleva al proceso de modernidad a su insuperable conclusión, como el proceso por el cual el sujeto humano como pura conciencia se emancipó y triunfó sobre el cuerpo humano" (2014: 1541).

En este pasaje afirma con claridad que la comunicación electrónica acabaría con la modernidad mediante la descorporeización, en un mundo como pura mente. Éste es un tema que ha desarrollado desde su propuesta programática de un campo no hermenéutico, allá por la década de 1980 (Gumbrecht, 2006). ${ }^{11}$ Pero, ¿cómo pensar en un nuevo cronotopo en este escenario? ¿Qué evidencias tenemos de una posible superación o anulación del cronotopo moderno? La principal evidencia sería la sensación general de desaceleración del tiempo, la cual anularía diversos aspectos de la modernidad, como ha sido formulada, en especial, en la descripción koselleckiana (Gumbrecht, 2012).

Inmediatamente después, insiste en que una percepción sensorial siempre soportará una reducción conceptual y en que el presente amplio digital está marcado por la posibilidad de simultaneidades temporales complejas. Esta simultaneidad digital que parece romper la noción de un tiempo lineal, carente de "progreso" historicista, ¿contradice o profundiza el cronotopo historicista? Al final, esta nueva "cascada de modernidad" no desarticularía todos los demás aspectos (Gumbrecht, 1998), sino que sería una forma de profundizar en las tendencias más esenciales de lo moderno y dejar de lado o transformar aquello que hoy puede parecer irrelevante para el historicismo. Las nociones de progreso y formación serían sustituidas por su actualización continua y acelerada: el actualismo. Como reveló nuestro recuento histórico de la palabra update, ésta absorbe parte de la carga semántica del concepto de progreso, ${ }^{12}$ fenómeno expuesto en la base de datos Google Books (véase la gráfica 3).

10 En un sentido similar, Hartog asegura que después de todo éste es "un mundo [...] que construye memoriales y los visita [...]. De tanto en tanto, nos concentramos en la respuesta inmediata a la inmediatez: se puede actuar en tiempo real, como en las caricaturas de los políticos" (2013: 100-101). Este punto fue representado en forma metafórica en el episodio "National Anthem" de la serie Black Mirror (Brooker, 2011-2017), en el que el primer ministro inglés tiene sexo en vivo con un puerco para rescatar a una princesa secuestrada. Para el historiador francés, habría una transición social e histórica "de la larga duración al todo-esacontecimiento" (2013: 263-266).

11 Para análisis recientes de la reflexión de Gumbrecht sobre la modernidad, véanse Brito (2014); Rangel y Rodrigues (2012); Rangel (2010); Araujo (2006); Ghosh y Kleinberg (2013). 


\section{Google Books Ngram Viewer}

Graph these comma-separated phrases: $\begin{array}{ll}\text { brogtess, update } \\ \text { between } 1800 \text { and } 2000 \text { from the corpus English }\end{array}$

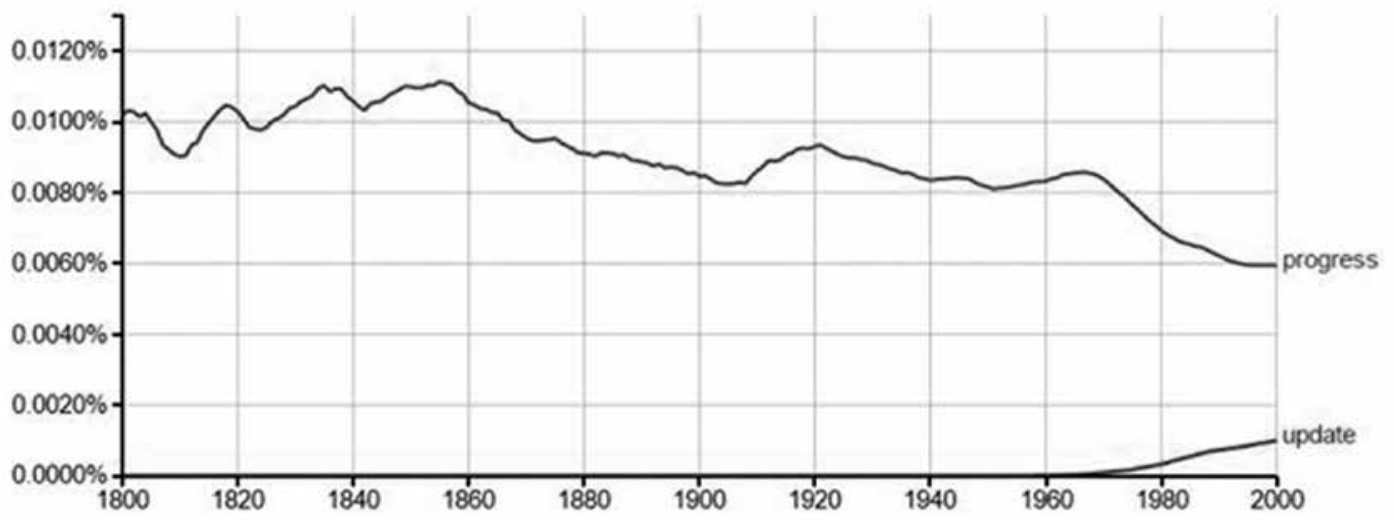

Fuente: Google Books Ngram Viewer. Consultado el 23 de junio de 2017.

Dice Gumbrecht que "en el presente electrónico de hoy, no hay nada 'del pasado' que necesitemos dejar atrás, ni nada 'del futuro' que no podamos traer al presente mediante una anticipación simulada" (2014: 72). La suma del pasado que no sucede y las anticipaciones resultaría en un “presente" largo y lento. No obstante, él mismo mantiene abierta la cuestión: "pero estoy al tanto de que esto no es más que otra revolución de las panteras grises" (2014: 72).

Entonces tenemos que el presente, como breve momento de transición, característico del historicismo, sería sustituido por las complejas simultaneidades del universo digital. El argumento depende de nuestra concordancia con dos afirmaciones: 1) que esta noción de presente fugaz en verdad haya sido hegemónica en el historicismo; 2) que las simultaneidades complejas la sustituirían en la desaceleración actual. Sin embargo, tal vez ese presente fugaz no haya sido tan hegemónico. Además de las diferencias de ritmo, hay una reproducción y permanencia del presente que puede identificarse incluso en el auge historicista. Aun amenazado por un futuro virtualmente superior, el historicismo producía una conciencia aguda del presente como el mejor de los tiempos, revelador-realizador del sentido histórico. En cuanto a la segunda afirmación, las simultaneidades actuales parecen ser típicamente impropias, tienen poco que ver con el instante y el

En este punto, nuestras conclusiones se apartan de los argumentos de Hartog, o los complejizan, en la medida en que para él: "la historia, la del régimen moderno de historicidad, con una $\mathrm{H}$ grande o una h pequeña, tenía fe en el progreso, marchaba hacia el futuro y mandaba con seguridad el pasado al pasado. Éste no podía más que pasar. Todo esto terminó y nos reencontramos cara a cara sólo con la memoria y el presente" (2013: 72). 
ahora como son tratados por autores como Benjamin (2005) y Heidegger (1993), a contrapelo del tiempo vacío y sucesivo del historicismo.

\section{Heidegger y las diversas temporalidades del presente ${ }^{13}$}

En el capítulo IV de la segunda sección de Ser y tiempo, dedicada al análisis de la temporalidad, Heidegger (2003: 324-359) habla de la cotidianidad del ser-ahí -Dasein-. Comienza por la constitución temporal de la comprensión, la disposición afectiva —Befindlichkeit-, la caída - Verfallen- y el discurso, entendidos como estructuras fundamentales. Aunque poseen temporalidades particulares, Heidegger encuentra la unidad estructural de la temporalidad en el conjunto de sus relaciones. Lo que queremos comprender en esta indagación es la multiplicidad de creencias de cada dimensión temporal: pasado, presente y futuro. Una buena parte de la literatura sobre historicidad ha considerado el presente como una dimensión autoevidente. Ahora veremos que esta estructura puede ser estudiada de otro modo y revelar sus posibilidades para la comprensión de nuestras temporalidades.

Nos faltaría espacio para estudiar las cuatro estructuras mencionadas por Heidegger. Sabemos que en su análisis cada dimensión temporal se atribuye a una estructura existencial de modo específico, su revelación corresponde al discurso. El pasado estaría relacionado en especial con la disposición afectiva, el futuro con la comprensión y el presente con la caída. Además, en cada estructura existencial — disposición afectiva, comprensión, caída-, las tres dimensiones temporales estarían siempre reunidas en acuerdos específicos —unidad extática-, tanto en modalidad "auténtica-propia" como en "inauténtica-impropia". Hablaremos sólo de las tres existencias que consideramos emblemáticas y convenientes para orientar nuestro argumento: la temporalidad de comprensión, enfocada en un futuro y asociada en particular a la autenticidad; la temporalidad de la caída, centrada en el presente y ejemplar para el entendimiento de los modos "impropios", y la temporalidad de la disposición afectiva.

La sección b del párrafo 68 trata la temporalidad de la disposición afectiva (Heidegger, 2003: 324-359). En Heidegger, la disposición afectiva aparece como la primera forma en la que el $D a-$ sein se relaciona con el mundo circundante. Incluso antes que cualquier comprensión, interpretación o discurso, el Dasein se encuentra en alguna disposición afectiva, en sintonía con algún clima. ${ }^{14}$ De hecho, las disposiciones surgen como una constelación específica de "humores", como miedo, angustia, tedio, rabia, etc. Así, toda la comprensión está ambientada, acorde o "sintonizada" con una configuración de humores o disposiciones. Heidegger se pregunta entonces por la constitución temporal de esa conexión entre humor y comprensión. ${ }^{15}$

El ambiente desplaza al ser-ahí de sí mismo y permite un estado de apertura para el entorno existente, o el ahí del ser-ahí. El ser-ahí, al ser lanzado a un mundo que lo precede, se abre hacia el pasado como la "fuerza de haber sido", es decir, aquello que forma parte del pasado pero se mantiene activo. Humores como miedo, angustia, tristeza y alegría son los primeros estados de apertura entre el ser-ahí y su ahí. Entonces, la forma temporal de la "fuerza de haber sido" como estructura existencial del ser-ahí está en la base de la disposición

\footnotetext{
13 Véase la nota 1.

14 Sobre las relaciones entre disposición y temporalidad, véase Lythgoe (2014).

15 Para una visión crítica de la reflexión de Heidegger sobre la historicidad, véase Trüper (2014). Sobre los usos político-académicos de la crítica a Heidegger en la reflexión teórico-historiográfica contemporánea, véase Kleinberg (2007).
} 
afectiva. Los éxtasis temporales restantes, porvenir y actualidad, por lo tanto, se modifican, como veremos en el análisis de la temporalidad de la comprensión y la caída.

Heidegger quiere demostrar la constitución temporal de la estructura ontológica del "estar acorde" —en sintonía—, es decir, de la disposición afectiva, "visibilizar la temporalidad del humor" (1993: 138). Por la temporalidad primaria del pasado, el humor tiene como carácter existencial básico "traer de regreso". Por ello, por su facultad de traer de vuelta, el humor siempre muestra una modalidad del pasado como la "fuerza de haber sido". En ese mundo que existe antes de que el ser-ahí sea lanzado hacia él, el humor es como un "salto de tigre" que se abre al mundo por vez primera. Así como el tigre que acecha a la presa "espera”, esa espera guarda en sí misma un "regreso", una vuelta, una expectativa.

En el capítulo IV, Heidegger intenta demostrar la temporalidad de dos humores que ya había examinado en la primera sección de la obra: el miedo y la angustia. Definido en la primera como "disposición afectiva impropia”, resulta evidente que en el temor entra en juego una dimensión del porvenir como espera. Siempre tememos a lo que viene a nuestro encuentro, la expectativa de un mal que se aproxima es una de las estructuras temporales del miedo. Pero ese futuro amenazador, en el humor del miedo, no es sólo un miedo de algo por venir, sino un miedo en sí mismo, un miedo al daño en el ahí. Ese miedo futuro que amenaza el ahí del Dasein en sus ocupaciones con las cosas y con otras personas tiene dos consecuencias: depresión - aflicción- y confusión - turbación- En la confusión del miedo, el Dasein tiende a olvidar sus posibilidades y se reduce a su ahí más inmediato, al que cree en riesgo. Al confundirse con su ahí o con su ser-ahí, prescinde de lo que le es más propio: su poder ser. En este olvido, se ocupa entonces de manera exclusiva de lo inmediato, de lo que está a su alcance. En la depresión, el ser-ahí se relaciona con su ser-lanzado - porvenir- en un sentido negativo, se aísla para el futuro, al que contempla como un mal que se acerca o que de nuevo lo lanza hacia lo inmediato en busca de protección: "presa del miedo, la ocupación salta de una posibilidad a otra, porque, al olvidarse de sí, no asume ninguna determinada" (2003: 331).

El mundo que circunda al ser-ahí, despojado de su futuridad, se oscurece, se experimenta como algo desconocido y extraño. El ser-ahí entonces pasa a actualizar — presentificar — lo más inmediato, que en su confusión considera que debe ser "protegido". Heidegger pone como ejemplo a las víctimas de incendios que, desesperadas por escapar, salvan los objetos más irrelevantes sólo porque están a su alcance, por ser inmediatos. En la urgencia del miedo, el ser-ahí se olvida de sí. Así, la temporalidad del miedo está anclada en una forma de pasado - la fuerza de haber sido- - el olvido, el cual a su vez modela futuro y presente — actual- : "la temporalidad del miedo es un olvido que, estando a la espera, hace presente" (2003: 331).

Ya en la angustia, el ser-ahí no teme por algo en particular ni por nada que tenga sentido temer. El ser-ahí se confronta con el vacío y la extrañeza del mundo al cual ha sido lanzado. El mundo de las ocupaciones cotidianas, que se toma como única realidad, pierde relevancia y el ser-ahí puede entonces desocuparse y abrir espacio para poder ser. El futuro en la angustia no puede ser el mismo del miedo, ya que, liberado de sus ocupaciones, el serahí no espera ni posee expectativas, pues se encuentra frente a sí mismo. Del mismo modo, el pasado no surge como olvido, sino como un estar abierto a la posibilidad de la repetición. Ya el presente se mantiene en la reubicación del haber sido lanzado, en la revelación del carácter de posibilidades de las situaciones que en el miedo parecen al mismo tiempo sólidas y siempre en peligro de desaparecer. Mientras que la angustia parece estar relacionada en particular con el futuro como decisión, el miedo se 
ancla en la actualidad de un presente siempre inestable en su aparente estabilidad.

Sin embargo, la estructura existencial de la caí$\mathrm{da}$-Verfallen - es la que encuentra su sentido prioritario en la "actualidad" — presente—, igual que la comprensión en el futuro y el humor en el pasado. De los tres fenómenos que Heidegger utiliza en Ser y tiempo para caracterizar la caída: rumor, ambigüedad y curiosidad, sólo la última recibe un análisis detallado de su temporalidad. La curiosidad se fundamentaría en la voluntad de "ver" y "ser visto", sin que el ser-ahí obtenga elementos de comprensión tras su encuentro con el ente. Esta visualización depende de su encuentro en un tipo especial de presente, que la edición brasileña ha traducido como actualidad: "la actualidad [Gegenwart] otorga un horizonte extático en el cual un ente puede estar vigente corporalmente [anwesend]" (1993: 145). ${ }^{16}$

Esa forma de presente como actualidad no está desprovista de futuro ni de pasado, sino que establece relaciones "impropias" con ambos. La caída es la única estructura existencial del ser-ahí que no conoce una forma “propia”, la propiedad del ser-ahí depende de la suspensión de la caída para decidir. La curiosidad se relaciona con el futuro y niega cualquier posibilidad de espera o expectativa, dado que todo aquello que le interesa debe estar "actualmente" a su alcance. El futuro se entiende como una suerte de espacio en el que las cosas "surgen", "emergen", y pueden ser vistas en la actualidad. El vínculo entre actualidad y futuro se vuelve opaco y oscuro, y aunque el ser-ahí huye de este vínculo, su curiosidad no se detiene: "la modificación extática del estar a la espera por medio de la presentación [actualización] que salta fuera, que convierte a ese estar a la espera en un estar a la espera que salta detrás, es la condición tempóreo-existencial de la posibilidad de la distracción" (2003: 336). ${ }^{17}$

En la caída, con frecuencia representamos el pasado como algo nuevo — modificado-. Así, el pasado abandona su modalidad "fuerza de haber sido" y se presenta como una simple modificación en la oscilación continua entre olvido y memoria. Esto genera una dispersión que nos hace percibir el tiempo del presente como un desamparo, estar en todos lados y en ninguna parte: "este modo del presente es el fenómeno máximamente opuesto al instante" (2003: 336).

Esa actualidad se observa a lo largo de toda la historia, sea presente o futura, pero se le identifica como una variedad, en la cual "la presentación presenta por mor del presente" (2003: 336). ${ }^{18}$ La imagen de un "presente amplio" o de un "presentismo" encuentra una filiación evidente en la temporalidad de la caída y nos ayuda a comprender lo paradójico de un presente que está al mismo tiempo lleno de novedades y vacío de sucesos. Por más que se presenten las novedades, sean del pasado o del futuro, no son capaces de reconstruir vínculos conjeturales, ya que "nuestra actualidad" se actualiza — casi- exclusivamente en función de la propia actualidad. Lo que ese movimiento puede reintroducir al argumento presentista es la aclaración de que no se trata sustancialmente de una ampliación del presente, sino de la ampliación de referencias al pasado y al futuro, sólo que en formas actualistas. Así, entendemos de qué manera la "moda" de la historia y de las cosas históricas puede ser contemporánea del presentismo. O cómo una sociedad con el futuro cerrado puede ser, al mismo tiempo, adicta a las novedades y al más reciente programa de televisión, película, juego en línea o gadget.

16 "Este dejar comparecer se funda en un presente. Dicho presente [Gegenwart] ofrece el horizonte extático dentro del cual el ente puede estar "personalmente" presente [anwesend]" (Heidegger, 2003: 335).

17 Como se indica entre corchetes, la versión de Marcia Sá Cavalcante (Heidegger, 1993) traduce Gegenwartigen por "actualización" (1993: 146) y Gegenwart por "actualidad" (1993: 145). Esta posibilidad es de particular interés para nuestra reflexión sobre el actualismo.

18 "Actualiza en función de la actualidad" (Heidegger, 1993: 146). 
Claro que para Heidegger el ser-ahí no está desprovisto de futuro y pasado en la caída; sin embargo, la continua actualización de lo actual, a lo que llamamos "actualismo", impide que el ser-ahí "se mire a sí mismo" (1993: 147). Repleto de novedades que transmiten la sensación de una aceleración creciente, pero que son incapaces de transformar o abrir la realidad a la posibilidad de la diferencia, en la caída al ser-ahí sólo le resta quedarse por siempre dentro de lo nuevo, up to date con una realidad en constante "surgimiento". Por eso, la "actualización automática", que parece brotar en nuestros celulares y computadoras, se vuelve irresistible, una metáfora y una estructura "arquetípica" de las temporalidades del actualismo.

Según la descripción que hace Heidegger de las estructuras ontológico-existenciales, se supone que estarían presentes en cualquier horizonte histórico. Por lo tanto, debemos entender la caída como una dimensión transhistórica. Entonces, lo que resta por dilucidar es qué factores parecen haber ampliado la visibilidad y disponibilidad de dicha temporalidad en nuestra contemporaneidad. También las sociedades tradicionalmente historicistas del siglo XX se movían la mayor parte del tiempo por la cotidianidad decadente; sin embargo, algo impedía que esa dimensión dominara la autorrepresentación social. Del mismo modo, no podemos asegurar que hoy tengamos una mayor oportunidad de distracción, aunque dicha distracción parece haberse convertido en una gran demanda social. Como si la vida fuera un carnaval de variedades interminable o un reality show. "Incluso cuando todo se ha visto, y precisamente entonces, la curiosidad inventa algo nuevo" (2003: 337). ${ }^{19}$

\section{Consideraciones finales}

A diferencia de la hipótesis de un dominio o aislamiento del presente, el actualismo puede pensarse como una forma específica de temporalidad, es decir, un modo de articular pasado, presente y futuro que parece haber cobrado relevancia en nuestra contemporaneidad. Esa forma de articulación naturaliza el "hoy", y por más que esté repleto de imágenes del pasado y del futuro, éstas no son capaces de transformar el horizonte. Algo en nuestra formación histórica parece favorecer la caída, de modo que el "actualismo" se expande en detrimento del instante que puede abrir horizontes temporales diversos. La expansión de las tecnologías comunicacionales habría ampliado las posibilidades de caer, pues ambivalencia, curiosidad y rumor parecen describir mucho de lo que sentimos y esperamos al crear una cuenta en redes sociales como Facebook, Instagram, Snapchat, Twitter, Periscope o WhatsApp. Tenemos la sensación de que lo "actual" surge de la actualización constante, como se ve a diario en los portales de noticias, los cuales operan bajo una lógica de producción de información cercana a la del mercado financiero, más aún en lo que respecta a escándalos y crisis políticas, o en la publicidad de un canal de televisión brasileño: "En 20 minutos todo puede cambiar". ${ }^{20}$ Nos sentimos libres para entregarnos a la diversidad del mundo. Pues si todo cambia todo el tiempo, nada cambia en realidad.

En el actualismo —updatism-, el presente nunca se adapta al pasado ni al futuro, considera que necesita actualizar constantemente esas dimensiones a su propio horizonte. Una relación más compleja con la temporalidad implicaría que el presente no sólo "actualizara" pasado y futuro, sino que además se volviera obsoleto en ellos (Araujo, 2013b). La perspectiva del actualismo naturaliza el presente como única realidad posible. Así, todo lo que no está "presente" necesita ser actualizado en el sentido estricto de "traído"

19 En este sentido, aunque desde un punto de vista metafórico, véase el episodio "Fifteen Million Merits", de la serie Black Mirror (Brooker, 2011-2017).

20 "Em 20 minutos, tudo pode mudar". Disponible en línea: <http://www.bandnewsfm.com.br/>. 
o "conservado" en el presente, lo que oscurece la unidad extática y horizontal de la temporalidad. Es pertinente retomar aquí una hipótesis de Koselleck, que dice que "la aceleración corresponde a una desnaturalización de la experiencia temporal conocida hasta el momento. Es un indicador de una historia específicamente moderna" (2014: 142).

La novedad se vuelve la norma, la palabra monotonía habla de un ánimo tibio, de un clima que no tiene un humor fuerte ni dominante, sino que se apaga en una disponibilidad igual de tibia que todos los humores. ${ }^{21}$ Nuestro problema aquí es conciliar la experiencia de aceleración contemporánea con la afirmación de que hoy es igual que ayer y mañana. Quizá exista la misma confusión entre "variedad” y "diferencia". En un mundo cada vez más familiar y cotidiano, la experiencia de desaceleración parece volverse más hacia la "variedad" creciente que hacia la "diferencia" creciente. Así podemos entender el gesto tan actualista de interpretar el pasado y el futuro como simples "variedades" del hoy, igual que una película ambientada en el pasado lejano o en el futuro parece representar los mismos valores y formas de vida del presente, sólo que con otras ropas. La aceleración que vivimos no sería entonces un simple alejamiento entre expectativa y experiencia de la forma, como fue teorizado por Koselleck; quizá él mismo confundió la percepción de la aceleración, que puede venir de la mayor diferencia como de la mayor variedad. Estas dos formas de la aceleración han experimentado expansiones propias de la modernidad.

En Ser y tiempo, las estructuras de la disposición afectiva y la comprensión permiten la ruptura con la "cotidianidad decadente". Sin embargo, como hemos visto, hasta esas dos estructuras pueden desarrollarse en una modalidad impropia o inauténtica, y la mayor parte de las veces así sucede. Así, también la comprensión se puede temporalizar de un modo más congruente con el actualismo, a pesar de su arraigo estructural en el futuro. En forma auténtica, la comprensión permite que el ser-ahí se proyecte en su poder ser, anticipe el futuro, repita el pasado en lo que queda vigente, e instaure con ello lo que Heidegger llama instante o momento -Augenblick - Ya en el modo impropio de la comprensión, el ser-ahí se relaciona con el futuro como espera. El presente está en continua actualización de los ahoras, que siempre oscilan entre olvido y memoria, y ocultan su procedencia exacta: "[la espera] que actualiza y olvida es una unidad extática [en sus propios términos], donde la comprensión impropia se temporaliza en su temporalidad" (Heidegger, 2010: 324). ${ }^{22}$

André Duarte (2010), a partir de Heidegger, sostiene que la realidad virtual creada por la tecnociencia de la informática adquiere el estatuto ontológico del "fondo de reserva subsistente" —Bestand-, con vistas a la gestión tecnológica. La realidad se transforma de manera progresiva en informaciones, diríamos, actualizadas sin cesar, todo el tiempo: "lo que parece ponerse en duda es el propio formateo tecnológico de la realidad como realidad virtual, esto es, como información dirigida técnicamente, en el curso de un proceso acelerado de virtualización" (Duarte, 2010: 187) [subrayado en el original].

El propio Heidegger ya anunciaba estas transformaciones en 1950 al afirmar, por ejemplo, que "mientras la cantidad de información se incrementa de modo desenfrenado, más decididamente se amplía el ofuscamiento y la ceguera ante los fenómenos" (citado en Duarte, 2010: 189). O incluso,

21 Un punto que debe ser investigado más a fondo es el de que en la serie Black Mirror (Brooker, 2011-2017), que hemos tomado como metáfora de nuestra condición actualista, el principal humor que se pone en evidencia es la apatía.

22 En la traducción inglesa: "Awaiting that forgets and makes present is an ecstatic unity in its own right, in accordance with which inauthentic understanding temporalizes itself with regard to its temporality". 
en 1996: "la técnica, en su esencia, es algo que los hombres no dominan por sí mismos [...]. La técnica arranca al hombre de la tierra y lo desarraiga cada vez más. El desarraigo del hombre ya está ahí. Sólo tenemos relaciones técnicas. El hombre ya no vive sobre la tierra" (citado en Duarte, 2010: 190). ¿Estamos frente a la imposibilidad de una relación libre o incluso de superación por el mundo de la técnica? Para Duarte, "en la medida en que cada vez más lo real, la naturaleza y el propio hombre sean producidos técnicamente, cada vez más tendrá sentido hablar de realidad virtual, de naturaleza virtual o artificial e incluso de la virtualización artificial del propio hombre" (2010: 12). Por lo tanto, lo que está en cuestión en nuestro tiempo es el propio hombre, su nacimiento y su muerte. ¿Cuál es el precio de la anulación o el retraso de la muerte por medio de la técnica? ¿De qué ente y ser estamos hablando?
¿De cuál estado de apertura, historia, memoria y olvido? La planeación, producción y manipulación casi total del nacimiento y la muerte no son sólo productos de la imaginación ficcional de series de Netflix, son también una realidad y un presentefuturo de nuestro mundo. La cuestión quizá no sea si todavía creemos en la historia (Hartog, 2013), sino cuáles son los peligros actuales de la condición histórica propia del hombre. Por otro lado, la experiencia moderna de la historia no ha demostrado ser capaz de fomentar con plenitud la experiencia democrática. Para no caer en la tentación del pesimismo fácil, ni de la nostalgia, dejamos claro que nosotros sí vemos alguna fuerza y nuevas conformaciones dispuestas a combatir el "nuevo sentimiento antidemocrático" (Rancière, 2014) en el interior de nuestra condición histórica actualista vigente. D

\section{Bibliografía}

Agamben, Giorgio, 2009, O que é o contemporâneo? e outros ensaios, Argos, Chapecó.

Arantes, Paulo Eduardo, 2014, O novo tempo do mundo e outros estudos sobre a era da emergência, Boi Tempo, São Paulo.

Araujo, Valdei Lopes de, 2006, "Para além da auto-consciência moderna: a historiografia de Hans-Ulrich-Gumbrecht”, en Varia História, vol. 22, núm. 36, pp. 314-328.

_ _ 2013a, "Die Beobachtung beobachten: über die Entdeckung der Historischen Stimmung und das Auftauchen des historistischen Chronotops um 1820", en Perla Chinchilla Pawling, Aldo Mazzuchelli y Hans Ulrich Gumbrecht (coords.), Beobachtung zweiter Ordnung im historischen Kontext: Niklas Luhmann in Amerika, Fink, Múnich, 99-114.

__ 2013b, "História da historiografia como analítica da historicidade", en História da Historiografia, núm. 12, pp. 34-44. Disponible en línea: <http://www.historiadahistoriografia.com.br/revista/article/view/620>. Consultado el 14 de octubre de 2014.

Benjamin, Walter, 2005, "Teses sobre o conceito de história”, en Michael Löwy, Walter Benjamin: aviso de incêndio. Uma leitura das teses "Sobre o conceito de história", Boitempo, São Paulo, pp. 33-146.

Bevernage, Berber, 2012, History, Memory, and State-Sponsored Violence: Time and Justice, Routledge, Nueva York.

Brito, Thiago Vieira de, 2014, O despertar da presença: a tensão epistemológica na filosofia da história de Gumbrecht, tesis de maestría en historia social de las relaciones políticas, Universidade Federal de Espírito Santo, Vitória.

Cameron, Robert M., 1967, Update: A Utility Program for the An/gyk-3(v) Modular Data Processing System, Defense Technical Information Center/Naval Research Lab, Washington, D. C.

Duarte, André, 2010, Vidas em risco: crítica do presente em Heidegger, Arendt e Foucault, Forense Universitária, Río de Janeiro.

Faria, Felipe, 2014, "O Atualismo entre uniformitaristas e catastrofistas", en Revista Brasileira de História da Ciência, vol. 7, núm. 1, pp. 101-109. Fontana, Josep, 1998, História depois do fim da história, Editora da Universidade do Sagrado Coração, Bauru.

Ghosh, Ranjan y Ethan Kleinberg (eds.), 2013, Presence: Philosophy, History, and Cultural Theory for the Twenty-First Century, Ithaca/Cornell University Press, Nueva York.

Gumbrecht, Hans Ulrich, 1998, Modernização dos sentidos, 34, São Paulo. 
_ 2006, "Presence Achieved in Language (with Special Attention Given to the Presence of the Past)", en History and Theory, vol. 45, núm. 3, pp. 317-327.

—_ 2012, Graciosidade e estagnação: ensaios escolhidos, Contraponto/Pontifícia Universidade Católica do Rio de Janeiro, Río de Janeiro. 2014, Our Broad Present: Time and Contemporary Culture, Columbia University Press, Nueva York.

Hartog, François, 2003, Régimes d'historicité: présentisme et expériences du temps, Seuil, París.

_ 2013, Croire en l'histoire, Flammarion, París.

Heidegger, Martin, 1977, The Question Concerning Technology, Garland, Nueva York.

__ 1993, Ser e tempo, trad. Márcia de Sá Cavalcante, Vozes, Petrópolis.

2003, Ser y tiempo, trad. Jorge Eduardo Rivera, Trotta, Madrid.

2006, Sein und Zeit, Max Niemeyer, Tübingen.

2010, Being and Time, trad. Joan Stambaugh, State University of New York Press, Nueva York.

Jordheim, Helge, 2014, "Introduction: Multiple Times and the Work of Synchronization”, en History and Theory, vol. 53, núm. 4, pp. 498-518. Disponible en línea: <http://doi.wiley.com/10.1111/hith.10728>.

Keen, Andrew, 2012, Digital Vertigo: How Today's Online Social Revolution Is Dividing, Diminishing, and Disorienting Us, Constable, Londres.

Kleinberg, Ethan, 2007, "Haunting History: Deconstruction and the Spirit of Revision”, en History and Theory, vol. 46, núm. 4, pp. 113-143. Disponible en línea. <http://doi.wiley.com/10.1111/j.1468-2303.2007.00431.x>.

Koselleck, Reinhart, 2014, Estratos do tempo: estudos sobre história, Contraponto/Pontifícia Universidade Católica do Rio de Janeiro, Río de Janeiro.

Lythgoe, Esteban, 2014, “Disposición afectiva y temporalidad en Martin Heidegger entre 1927 y 1930”, en Aurora, vol. 26, núm. 39, pp. 759-775.

Menzel, Christopher, 2014, "Actualism”, en Stanford Enciclopedia of Philosophy, Center for the Study of Language and Information-Stanford University, Stanford. Disponible en línea: <http://plato.stanford.edu/entries/actualism/>. Consultado el 14 de octubre de 2014.

Nicolazzi, Fernando, 2010, "A história entre tempos: François Hartog e a conjuntura historiográfica contemporânea”, en História: Questões \& Debates, núm. 53, pp. 229-257.

Pereira, Mateus y Sérgio Ricardo da Mata, 2012, "Transformações da experiência do tempo e pluralização do presente”, en Flávia Varella et al. (coords.), Tempo presente e usos do passado, Fundação Getúlio Vargas, Río de Janeiro, pp. 9-30.

Pereira, Mateus, Pedro A. C. dos Santos y Thiago L. Nicodemo, 2015, "Brazilian Historical Writing in a Global Perspective: On the Emergence of the Concept of 'Historiography"', en History and Theory, vol. 54, núm. 4, pp. 84-104.

Rancière, Jacques, 2014, O ódio à democracia, Boitempo, São Paulo.

Rangel, Marcelo de Mello, 2010, "Sobre a utilidade e desvantagem da ciência histórica, segundo Nietzsche e Gumbrecht”, en Dimensões, vol. 24, pp. 208-241. Disponible en línea: <http://www.periodicos.ufes.br/dimensoes/article/view/2531/2027>.

Rangel, Marcelo de Mello y Thamara de Oliveira Rodrigues, 2012, "História e modernidade em Hans Ulrich Gumbrecht" en Redescrições, año 4 , núm. 1, pp. 63-71. Disponible en línea: <http://www.gtpragmatismo.com.br/redescricoes/redescricoes/ano4_01/gum_marcelo_e_ thamara.pdf>. Consultado el 17 de octubre de 2014.

Ricoeur, Paul, 2000, La mémoire, l'histoire, l'oubli, Seuil, París.

_ 2012, "A marca do passado", en História da Historiografía, núm. 10, pp. 329-349.

Trüper, Henning, 2014, "Löwith, Löwith’s Heidegger, and the Unity of History”, en History and Theory, vol. 53, núm. 1, pp. 45-68. Disponible en línea: <http://doi.wiley.com/10.1111/hith.10694>. Consultado el 6 de octubre de 2014.

Zermeño, Guillermo, 2008, "História, Experiência e Modernidade na América Ibérica, 1750-1850", en Almanack Braziliense, núm. 7, pp. 5-46.

\section{Filmografía}

Brooker, Charlie (dir.), 2011-2017, Black Mirror, serie de televisión, Zeppotron/Channel 4/Gran Babieka, Londres. 